\title{
A case report on an unusual degeneration of uterine leiomyoma: Myxoid degeneration
}

\section{Paneru $\mathbf{R}^{1}$, Thapa $\mathbf{M}^{2}$}

${ }^{1}$ Rupa Paneru, Resident; ${ }^{2}$ Meena Thapa, Associate Professor, Department of Obstetrics/Gynecology, Kathmandu Medical College, Kathmandu, Nepal.

\begin{abstract}
Background: Leiomyomas are benign smooth muscle neoplasm that typically occurs from the myometrium. Most of the women with uterine leiomyoma remain asymptomatic. Various degeneration including hyaline, cystic, myxoid and red degeneration and dystrophic calcification occur in leiomyoma, among them myxoid degeneration occurs rarely. Here is a case report of 40 years with one living child and two abortions who came with complaints of feeling of heaviness and pain at lower abdomen for six months, palpable lower abdominal mass for four months and difficulty in passing urine since 15 days. Multiple fibroids with cystic degeneration were suspected in Computed Tomography scan report. The patient underwent Total Abdominal Hysterectomy with Bilateral Salphingectomy. On cut section there was a cystic area on the body of uterus containing 1.1 liter of straw coloured fluid. Final histopathological findings concluded multiple leiomyoma with myxoid degeneration.
\end{abstract}

Key words: Degeneration; Leiomyoma; Myxoid.

DOI: https://doi.org/10.3126/jkmc.v7i4.23325

\section{INTRODUCTION}

$\mathrm{L}$ eiomyoma also known as fibroid is the most common benign tumor of uterus. Twenty percent of the women at the age of 30 have got leiomyoma in their womb but most of them remain asymptomatic ${ }^{1}$. As leiomyomas enlarge, they may outgrow their blood supply, which results in various types of degeneration including hyaline, cystic, myxoid and red degeneration and dystrophic calcification².

Generally, the sonographic appearance of uterine leiomyomas is characteristic however, they can undergo various kinds of degeneration that can dramatically change their sonographic appearance and make the diagnosis quite challenging ${ }^{3}$. Myxoid degeneration is a rare change accounting for $19 \%$ of the cases and its clinical diagnosis is difficult as there is no relationship between symptomatology and the presence of these changes ${ }^{4}$.

Address for correspondence

Dr. Rupa Paneru

Resident, Department of Obstetrics/Gynecology

Kathmandu Medical College, Kathmandu, Nepal

E-mail: dr.rupapaneru@gmail.com
Although fibroids typically have a characteristic ultrasonography appearance, degenerating fibroids can have variable patterns, can pose diagnostic challenges and sometimes the confusion is so much that the clear picture is revealed only at laparotomy or after histopathological report ${ }^{5}$.

\section{CASE REPORT}

A 40 year old lady, one living child with two abortions (P1L1A2), came to the Department of Obstetrics and Gynecology, Kathmandu Medical College with complaints of pain at lower abdomen for four months which was gradual in onset, dull aching, located at subumblical region, non-radiating and non-migratory type, aggravated while bending down and relieved on lying down with a sense of heaviness in the lower abdomen. She also gave history of mass felt per abdomen which had suddenly increased in its size for 15 days since then she had developed difficulty while passing urine with sense of incomplete evacuation with each voiding. However there was no history of difficulty in passing stool, fever, loss of appetite and weight loss. Her menstrual cycle was regular and normal. There was no past history of hormonal therapy and malignancy. There was no history of malignancy in family members as well. 
On clinical examination she was well built without pallor, edema and lymphadenopathy. Abdominal examination revealed a uniform smooth surface with regular margin and non-tender mass of 22 weeks uterine size, appeared to be arising from pelvis. Lower pole of the mass could not be reached. On per speculum examination, cervix was healthy. On per vaginal examination, enlarged uterus of 22 weeks size, mobile, non-tender and firm. Bilateral fornices were full but non-tender. Per rectal examination revealed no mass in the rectum.

On investigations hemoglobin level was $13.8 \mathrm{gm} \%$, total and differential blood counts, platelets counts, Renal function test, blood sugar level all were within normal limits. Cancer Antigen 125 (CA125) was $193.2 \mathrm{U} / \mathrm{ml}$ and Carcinoembryonic Antigen (CEA) was $2.1 \mathrm{ng} / \mathrm{ml}$.

Trans-abdominal sonography revealed bulky uterus of $11.5 \times 6.5 \times 6.1 \mathrm{~cm}^{3}$ size with hypoechoic lesion measuring $3.7 X 3.4 \mathrm{~cm}^{2}$ at lower body of the uterus.

The computed tomography of abdomen and pelvis showed bulky uterus of $19 \times 16 \mathrm{X} 15 \mathrm{~cm}^{3}$ with multiple enhancing lesions seen in the wall of uterus largest one measuring $15 \times 13 \times 10 \mathrm{~cm}^{3}$ with central non-enhancing areas within. No calcification and fat component seen and reported as multiple fibroids with cystic degeneration.

She was planned for abdominal hysterectomy. Vertical midline incision was given and abdomen was opened. Total Abdominal Hysterectomy (TAH) with bilateral salphingectomy was done.

Per operative findings revealed grossly enlarged uterus weighing 2.2 kilograms with irregular surface, largest bulge at left fundosuperior aspect measuring $8 \times 8 \times 7 \mathrm{~cm}^{3}$ with small subserosal fibroid of $2 \times 2 X 1 \mathrm{~cm}^{3}$ at the anterior wall of uterus. Bilateral tubes were stretched up and ovaries were normal. On cut section, utero cervical length was $14 \mathrm{~cm}$ and empty. Cavity of $8 \times 8 \times 7 \mathrm{~cm}^{3}$ containing 1.1 liter of straw coloured fluid with fleshy floor was found.

\section{REFERENCES}

1. Dutta D. Benign lesion of the uterus. In: Koner $\mathrm{H}$, editor. DC Dutta's Textbook of Obstetrics. $9^{\text {th }}$ ed. New Delhi: Jaypee Brothers Medical Publisher; 2018. P224-5.

2. Kaushik C, Prasad A, Singh Y, Baruah BP. Case seriesCystic degeneration in uterine leiomyomas.Indian $J$ radiology and imaging. 2008;18(1):69-72. [Full Text]

3. Neena M, Reddy MD, Kiran A. A Degenerating Cystic Uterine Fibroid Mimicking an Endometrioma on Sonography.Journal of ultrasound in medicine.2003; 22(9):973. [DOI]
Four intramural fibroids, at right fundosuperior aspect of uterus with whorled appearances, largest measuring $4 \times 4 \times 2 \mathrm{~cm}^{3}$.

Histopathology report showed multiple leiomyoma with myxoid degeneration.

Her post-operative period was uneventful and she had been discharged on fifth post-operative day.

\section{DISCUSSION}

Uterine fibroids, also known as myomas or leiomyomas, are the commonest of all pelvic tumors of women in the reproductive age group and increasing with age ${ }^{6}$. Various degenerations can be seen in leiomyomas and among them hyaline being the most common accounting $63 \%{ }^{4}$.

Myxoid leiomyomas are the degenerated leiomyoma composed primarily of smooth muscle cells, with significant accumulation of a cellular material rich in acid mucins ${ }^{7}$. Broad ligament fibroid with myxoid degeneration can mimic the ovarian tumor and its clinical diagnosis is difficult. One case had been reported by R. R. Godbole et al. and concluded that broad ligament fibroid with myxoid degeneration with inconclusive diagnostic report can have high suspicion of ovarian malignancy and final diagnosis always remains histopathological.

M Chaouki et al. also concluded that myxoid leiomyoma of the uterus is a rare benign tumor and it's diagnosis remains histopathological and leiomyosarcoma should always be ruled out ${ }^{7}$.

\section{CONCLUSION}

Myxoid degeneration of leiomyoma is a rare condition and it is difficult to diagnose clinically. Sometimes it mimics the picture of cystic degeneration of uterine leiomyoma and ovarian tumor. In such cases the final diagnosis can be reached only after histopathological reports.

4. Rosai J. Surgical pathology. $10^{\text {th }}$ ed.United States:Elsevier; 2011.p1510.

5. Panda SR, Chandra C. A rare case of leiomyoma of uterus with cystic degeneration. Int J ReprodContraceptObstet Gynecol. 2015; 4:863-5. [Full Text]

6. Godbole RR, Lakshmi KS, Vasant K. Rare case of giant broad ligament fibroid with myxoid degeneration. J Sci Soc. 2012;39:144-6. [Full Text ]

7. Chaouki M, Marouen N, Najet BM, Zied K, Anis $B A$, Hedhili O. An unusual presentation of uterine leiomyoma: Myxoid leiomyoma. International Journal of Case Reports and Images. 2012 33:13.[DOI] 